\title{
Potential of Black Rice (Oryza sativa L.) as Anticancer Through Mortalin-p53 Complex Inhibitors
}

\author{
Fadjar Kurnia Hartati ${ }^{1, *}$, Arlin Besari Djauhari ${ }^{1}$ \\ 1 Department of Food Technology, Faculty of Agriculture, Dr. Soetomo University, Indonesia \\ * Correspondence: fadjar.kurnia@ unitomo.ac.id;
}

Scopus Author ID 57194443683

Received: 23.04.2020; Revised: 5.05.2020; Accepted: 7.05.2020; Published: 12.05.2020

\begin{abstract}
This research was conducted because the number of cancer patients continues to increase so it is very necessary to look for food that has the potential as an anticancer, including black rice (Oryza sativa L.). The research method uses a docking method to identify bioactive compounds in black rice which act as anticancer through the mortalin-p53 complex inhibitor. The analysis showed that the campesterol compound contained in black rice has the potential as a cancer drug that has a mechanism that is by binding to the binding site ligand on mortalin so that it can inhibit the occurrence of the mortalin-p53 complex.
\end{abstract}

Keywords: Black Rice; Anticancer; P53; Mortalin; Campesterol.

(C) 2020 by the authors. This article is an open access article distributed under the terms and conditions of the Creative Commons Attribution (CC BY) license (https://creativecommons.org/licenses/by/4.0/).

\section{Introduction}

Black rice (Oryza sativa L.) is a special type of rice that has been consumed since long ago in China and Southeast Asia [1], because black rice has two advantages, namely as a staple food and also as a potent drug. This is because black rice contains components of phenol/flavonoid [2] compounds that can give a positive response to the cytolytic and proliferative lymphocyte cells, but are toxic and antiproliferative in cancer cells [3].

Several studies have shown that phenol/flavonoid compounds derived from plants show anticancer activity [4] by modulating cell cycle [5] regulation and/or apoptosis [6]. Failure of the apoptosis process in pathways often results in mutases of the p53 gene [7]. The p53 gene is a tumor suppressor gene [7] that accumulates when DNA is damaged and serves to prevent the replication of genetically damaged cells through cessation of the cell cycle phase of the interface (G1) so that the cell can repair [8]. If cell damage is quite extensive and there is a failure of repair, then this gene that functions triggers apoptosis [9].

\section{Materials and Methods}

The method used in this study includes the following stages:

\subsection{Preparation of protein samples and ligands.}

The 3D structure of chemical compound samples obtained from the database of chemical compounds (pubchem.ncbi.nlm.nih.gov), samples are stored in the format data structure format (sdf), then minimization of the OpenBabel program for the preparation of the molecular docking analysis phase. Sequences of target protein samples, p53 (ID P04637) and 
mortalin (ID P38646.2) were obtained from the Uniprot database (www.uniprot.org) and NCBI (www.ncbi.nlm.nih.gov) in the FASTA format [10].

\subsection{Protein modeling.}

Protein mortal and p53 modeling were carried out at the protein modeling webserver, Swiss Model (swissmodel.expasy.org), with the method used, was homology modeling [11]. The homology modeling process produces a homologous protein structure that has conserved protein sequences, but sequences with similarity values below $20 \%$ are stated to have different structures with templates. The modeling results will be validated using the RAMPAGE webserver (mordred.bioc.cam.ac.uk/ rapper/rampage.php) to determine the quality of the modeling results [12].

\subsection{Small molecule docking.}

This study uses molecular docking analysis to determine the binding energy of chemical compounds contained in black rice when binding to mortalin. The molecular docking software used is PyRx [13]. Grid docking is directed at the cofactor region of the target protein region [14], which was previously predicted to use the COFACTOR webserver (zhanglab.ccmb.med.umich.edu/COFACTOR/).

\subsection{Analysis of ligand, protein, and molecular visualization interactions.}

The type of chemical interactions that occur between protein ligands after experiencing docking, identified with the LigPlot software, can analyze the type and distance of chemical interactions in the molecular complex that is formed [15]. Visualization of results for molecular simulation in this study using Pymol software (pymol.org) [16].

\subsection{Protein docking protein.}

PatchDock (bioinfo3d.cs.tau.ac.il/PatchDock) is a web server that is used to simulate and predict interactions between proteins and complex macromolecules with rigid molecular docking, to obtain information in the form of conformational structures and atomic interaction energy (ACE) [17]. The results of PatchDock can be inputted into the FireDock web server to perform the refinement docking step to obtain flexible structures or protein complexes, the results of FireDock are one of them is the Van der Waals bond energy, and the molecular complex. The use of PatchDock and FireDock in this study is to compare the differences in chemical interaction energy of each atom making up the protein ligand complex [18], when mortalin interacts with p53 in normal conditions with mortalin which has bound to the query compound for black rice.

\section{Results and Discussion}

Sixteen compounds from the chemical compounds contained in black rice (Table 1) with 3D structures were obtained from the Pubchem database (pubchem.ncbi.nlm.nih.gov). Pubchem is a database of chemical compounds and biological assay which is part of the central database, NCBI, in the Pubchem database there are various kinds of information, namely molecular weight, pharmacology, MSDS, toxicity. About 93.9 million compounds have been successfully published in the Pubchem database since the end of 2014 [19]. 
After a chemical compound sample is obtained, protein modeling is carried out on the Swiss Model webserver (swissmodel.expasy.org). The homology modeling process produces a homologous protein structure that has conserved protein sequences, but sequences with similarity values below $20 \%$ are stated to have different structures with templates [20]. Protein modeling results of p53 and mortalin (Figure.1) have a similarity score with templates above $20 \%$ respectively, which shows that the two protein modeling results have a high similarity with template proteins. The 3D structure of $\mathrm{p} 53$ protein and mortalin was then analyzed for the quality of the model using the RAMPAGE server mordred.bioc.cam.ac.uk/ rapper/rampage.php). The results showed that the 3D structure of the two proteins each had a score of $92 \%$, indicating that the quality of the two protein models was very good because according to [21] the quality of the protein model must have a score of at least $90 \%$ of the favored region.
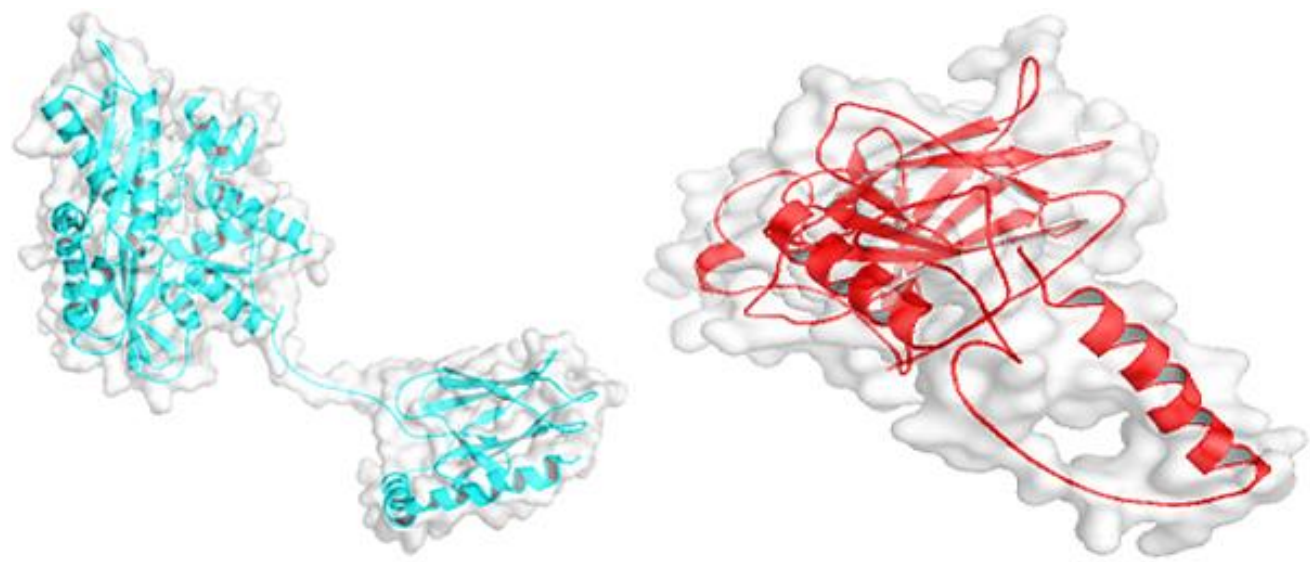

Figure 1. Structure 3D of protein mortalin and p53 results from homology modeling. Visualization of chain staining in the form of transparent surface structures containing cartoons colored cyans (mortalin) and red (p53) in PyMol software.

The position of the ligand binding site on the mortalin protein is unknown, so further analysis must be carried out on the COFACTOR webserver (zhanglab.ccmb.med.umich. Edu/COFACTOR /). This web server functions to predict the active side of a protein based on the cofactor region. The cofactor region is an area that is not akif on the enzyme which if attached to a ligand attached to it will cause changes in the biological function of a protein or enzyme [22]. Thus, the amino acid residue domain of the mortalin protein was obtained as the candidate binding site (Figure. 2), namely, in model 1 with amino acid residues Gly177, Gly176, Gly205, Glu243, Lys246, Cys247, Ser250, Met322, Arg321, Met319, Gly318, Gly317, predictive score or Cscore of 0.59 is greater than other models and the value of conv or coverage is $66.3 \%$. Model 1 is used because it has the highest Cscore value and between 01 , which means that the activedomain is very reliable as a ligand binding site [23]. After the ligand binding site on protein mortalin is known, then a virtual screening analysis is performed in the form of small molecule docking which aims to determine the size of the binding affinity of query compounds derived from black rice when interacting with mortalin. Most molecular docking methods are used to design drugs computationally, based on their purpose for screening the potential of a compound, this method is also divided into 2 namely reverse docking and docking inverse. Reverse docking is a docking that is done with the aim of finding binding sites on query compounds that have the lowest energy score when binding to the target protein domain, by clustering software to find low energy binding positions [24]. 


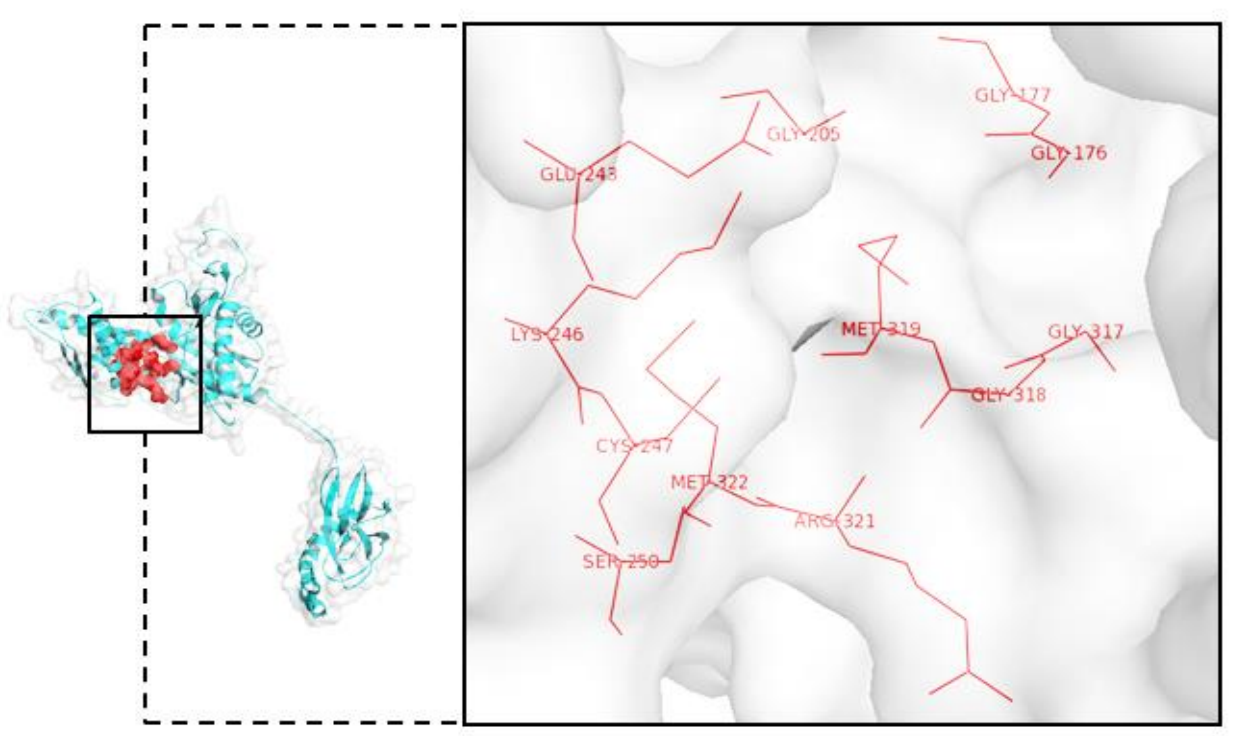

Figure 2. Visualization of the ligand binding site. The ligand binding site domain of mortalin is displayed with the structure of spheres and amino acid residues which comprise the domain in the form of lines of red, each of which is a structure.

Binding affinity, which means binding energy between ligands and proteins, the more negative the energy is, the more likely it is to form ligand protein complexes and shows that the more potential a ligand affects the physiology of a target protein [25]. The amount of binding affinity is an indicator of the ability possessed by active compounds in the target protein. That includes spontaneous processes, the bond between protein and ligand occurs due to the alteration in the negative system of the Gibs free energy $(\Delta \mathrm{G})$ when it reaches a state of equilibrium at constant pressure and temperature because the association between protein and ligand determines the negative value of $\Delta \mathrm{G}$, it can be studied to establish $\Delta \mathrm{G}$ can provide stability in protein-ligand complexes [26,27]. The analysis result of protein and ligand interaction can be seen in Table 2 .

This study uses PyRx software to simulate molecular docking [13], the grid docking is directed at the center coordinate position $\mathrm{x}: 102.41(\AA), \mathrm{y}: 61.08(\AA), \mathrm{z}: 2.73(\AA)$ and dimensions x: $20.83(\AA), y: 23.50(\AA)$, z: $20.46(\AA)$. The small molecule docking results (Table 1) show that campesterol has the lowest binding affinity compared to fifteen other compounds, which indicates that campesterol has the potential to form protein ligand complexes with mortalin and these compounds can affect the biological activity of target proteins [28].

After knowing the binding affinity value of each query compound, the next analysis stage is the interaction of proteins and ligands, in this study using the LigPlus software. LigPlus is commonly used to analyze the types of chemical bond interactions and the position of amino acid residues that interact with computational target ligands. The chemical bond interactions formed are hydrophobic interactions and hydrogen bonds [29]. This study uses the LigPlus software aimed to find out the possibility that query compounds can interact with the ligand binding site that was previously predicted. The results of the LigPlot analysis show that almost all query compounds are adequate in interacting with the ligand-binding site except omarigliptin compounds because the compound is tethered not to the position of the expected amino acid residue. Compounds that have the lowest binding affinity value, namely campesterol, interact with the ligand binding site with hydrophobic interactions, namely the amino acid residues Cys247, Gly318, and Arg321 (Figure. 4). 
Table 1. Score of docking results.

\begin{tabular}{c|c|c} 
Ligand & Target Protein & $\begin{array}{c}\text { Binding affinity } \\
\text { (kcal/mol) }\end{array}$ \\
\hline CAMPESTEROL & Mortalin & $-6,5$ \\
CYA-3-O-ARAB & Mortalin & $-6,2$ \\
CYA-3,5-DIGLU & Mortalin & $-6,2$ \\
QUER-3-O-RUTEIN & Mortalin & $-6,1$ \\
CYCLO & Mortalin & $-5,9$ \\
CYA-3-O-GLU & Mortalin & $-5,8$ \\
PEON-3-O-GLU & Mortalin & $-5,8$ \\
QUER-3-O-GLU & Mortalin & $-5,8$ \\
BETA-KAROTENE & Mortalin & $-5,6$ \\
ISHOR-3-O-GLU & Mortalin & $-5,6$ \\
PELAR-3-GLU & Mortalin & $-5,6$ \\
ZEAXANTHIN & Mortalin & $-5,4$ \\
OMARIGLIPTIN & Mortalin & $-5,3$ \\
LUTEIN & Mortalin & $-5,0$ \\
LYCOPENE & Mortalin & $-4,0$ \\
METHYLENE-FERULATE & Mortalin & $-3,8$
\end{tabular}

Table 2. Results of analysis of protein and ligand interactions.

\begin{tabular}{|c|c|}
\hline \multirow{3}{*}{$\begin{array}{l}\text { Ligand } \\
\text { CAMPESTEROL }\end{array}$} & Interactions \\
\hline & $\begin{array}{l}\text { Hydrophobic : } \underline{\text { Cys } 247} \text {, Lys36, Met33, Thr16, Ala14, Gly318, Asp344, } \\
\text { Asn342, Arg321 }\end{array}$ \\
\hline & Hydrogen : Arg15, Ser250 \\
\hline \multirow[t]{2}{*}{ CYA-3-O-ARAB } & Hydrophobic : Cys247, Pro343, Arg15, Pro18, Asn342 \\
\hline & Hydrogen : Arg321, Lys36, Met33, Arg239 \\
\hline \multirow[t]{2}{*}{ CYA-3,5-DIGLU } & Hydrophobic : $\underline{\operatorname{Ser} 250}$, Glu345, Arg15, Glu243, Met319 \\
\hline & Hydrogen : Gly318, $\operatorname{Arg} 321$ \\
\hline QUER-3-O-RUTEIN & $\begin{array}{l}\text { Hydrophobic: Met33, Thr16, Pro18, Met319, Ala14, Asp344, Gly177 } \\
\text { Hydrogen : Arg239, Glu206, Glu243 }\end{array}$ \\
\hline CYCLO & $\begin{array}{l}\text { Hydrophobic : Pro18, Thr16, Glu206, Met33, Met319, Lys36, Arg37, Glu243, } \\
\text { Glu204 } \\
\text { Hydrogen : - }\end{array}$ \\
\hline CYA-3-O-GLU & $\begin{array}{l}\text { Hydrophobic : Cys } 247, \text { Glu248, Met319, Arg321, Gly318 } \\
\text { Hydrogen : } \underline{\text { Ser } 250}, \text { Ser251, Asp344 }\end{array}$ \\
\hline PEON-3-O-GLU & $\begin{array}{l}\text { Hydrophobic : Arg } 37, \text { Met } 33 \text {, Glu206, Arg239, Glu240 } \\
\text { Hydrogen : Lys } 36, \text { Glu243, Gln236 }\end{array}$ \\
\hline QUER-3-O-GLU & $\begin{array}{l}\text { Hydrophobic: Gly205, Lys } 36, \text { Met319, Met33, Pro18, Thr16 } \\
\text { Hydrogen : Lys246, Glu243, Glu206, Gly177, Asp344 }\end{array}$ \\
\hline BETA-KAROTENE & $\begin{array}{l}\text { Hydrophobic : } \underline{\text { Glu} 243} \text {, Lys } 36, \text { Arg239, Glu240, Lys244, Glu248, Ser252, } \\
\text { Ser251 } \\
\text { Hydrogen : - }\end{array}$ \\
\hline ISHOR-3-O-GLU & $\begin{array}{l}\text { Hydrophbic : Gly318, Met319, Cys247, Ser250, Arg321, Glu248 } \\
\text { Hydrogen : Asp344, Ser251, Asn342 }\end{array}$ \\
\hline PELAR-3-GLU & $\begin{array}{l}\text { Hydrophobic : } \underline{\operatorname{Cys} 247}, \text { Glu248, } \underline{\operatorname{Arg} 321}, \text { Gly318, } \underline{\operatorname{Met} 319} \\
\text { Hydrogen : Ser251, } \underline{\operatorname{Ser} 250}, \text { Asp344 }\end{array}$ \\
\hline ZEAXANTHIN & $\begin{array}{l}\text { Hyrophobic : Glu248, } \underline{\text { Glu2 } 43} \text {, Ser252, Glu240, Lys244, Cys247, Gln236, } \\
\text { Arg37 } \\
\text { Hydrogen : Lys } 36\end{array}$ \\
\hline OMARIGLIPTIN & $\begin{array}{l}\text { Hydrophobic : Asp344, Thr16, Met33, Pro18, Lys36 } \\
\text { Hydrogen : Arg15 }\end{array}$ \\
\hline LUTEIN & $\begin{array}{l}\text { Hydrophobic : Met33, Lys36, Arg37, Glu243, Lys244, Glu248, Ser251 } \\
\text { Hydrogen : } \underline{\operatorname{Ser} 252}\end{array}$ \\
\hline LYCOPENE & $\begin{array}{l}\text { Hydrophobic : Pro18, Glu243, Met33, Glu240, Arg239, Gln236, Lys36, Arg37 } \\
\text { Hydrogen : - }\end{array}$ \\
\hline METHYLENE-FERULATE & $\begin{array}{l}\text { Hydrophobic : Met } 33, \text { Glu243, Pro18, Ala14 } \\
\text { Hydrogen : Arg239, Glu206, Lys36 }\end{array}$ \\
\hline Predicted Binding Site & 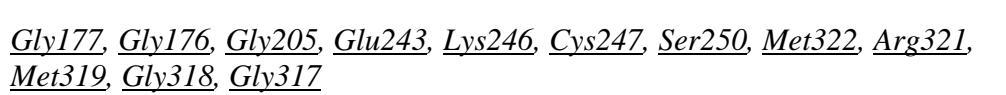 \\
\hline
\end{tabular}

Active compounds predicted to have strong bonds to target receptors or proteins if they can bind through hydrogen bond interactions and can bind to the same amino acid residue position in the ligand binding site [24]. So the predicted compound has a strong ability to inhibit a receptor or protein, ie if there are several amino acid residue positions similar to predicted binding sites or controls. Hydrogen bonds are electrostatic interactions between hydrogen 
atoms that bind to electronegative atoms and other atoms. The strength of hydrogen bonds is under covalent bonds, but their presence is very important because it involves the structure and characteristics of a molecule. In medicine, hydrogen bonds are used to study the design and interaction between drug molecules and system metabolism [30]. The results of ligand protein interaction analysis showed that the campesterol compound has a hydrogen bond with a ligand binding site on Ser250 amino acid residues (Figure. 4), one can assume that the compound can be a protein mortalin inhibitor.

When conditions for mortalin protein cancer will interact with p53 by direct binding [7]. This study uses PatchDock and FireDock webserver to simulate the conditions in which the mortalin protein interacts with p53 when it has not and already has inhibitors of the query compounds contained in black rice which are binding with the ligand binding site on protein mortalin.

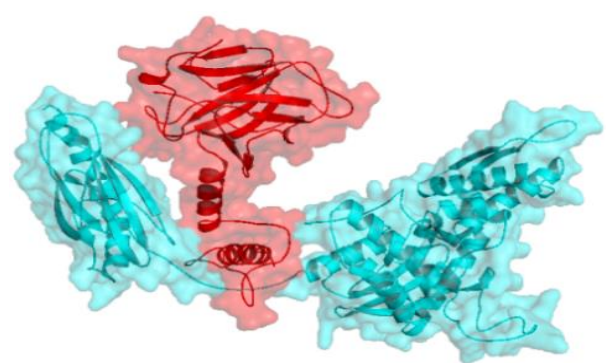

Figure 3. Visualizing the p53 complex with mortalin without bioactive compounds, the structure of the mortalin protein is displayed in the form of transparent surfaces and cartoon structures with color cyans while the p53 protein is red.

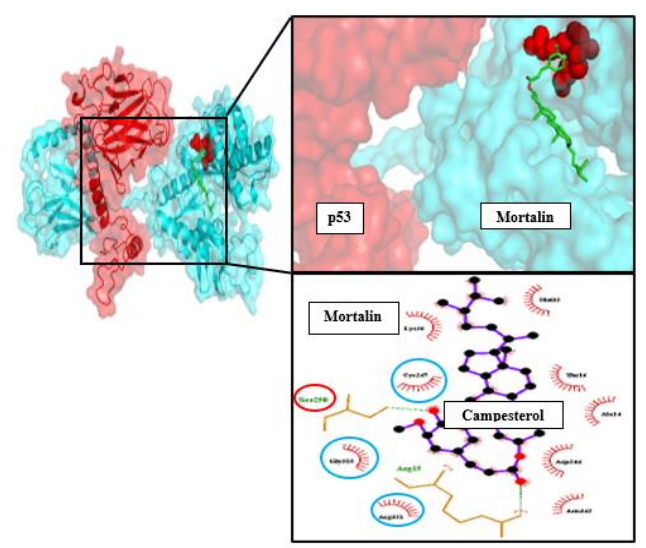

Figure 4. Visualization of the p53-mortal-campesterol complex. The ligand binding site is displayed in the structure of red colored spheres and green colored ligands in the sticks structure. Cyans and red colored circles on the analysis of ligand protein interactions show the position of the ligand binding binding site amino acid residues in the mortalin that interact with the campesterol compound.

The results of protein docking analysis which is in the form of bond energy ( $\mathrm{kcal} / \mathrm{mol})$, show that when the mortalin-p53 complex is formed in the absence of inhibitors (Figure. 3), the attractive Van der Waals energy is $-37.26 \mathrm{kcal} / \mathrm{mol}$ and $+46.68 \mathrm{kcal} / \mathrm{mol}$ for repulsive. But after there is a campesterol ligand that binds to the ligand binding site in mortalities there is a change in Van der Waals energy (attractive and repulsive), which is -18.90 $\mathrm{kcal} / \mathrm{mol}$ and $+165.90 \mathrm{kcal} / \mathrm{mol}$ respectively in the mortalin-p53 complex (Figure. 4). Van der Waals force which consists of attractive and repulsive contributes to the formation of the value of binding affinity and complex stability formed on a molecule when interacting with other molecules [26]. 


\section{Conclusions}

Based on the results obtained, this research concludes that the campesterol compound contained in black rice has the potential as a cancer drug that has a mechanism that is by binding to the binding site ligand on mortalin so that it can inhibit the occurrence of the mortalin-p53 complex. The bond of campesterol compounds in mortalin resulted in instability of the p53 mortalin complex which was characterized by the addition of attractive and repulsive Van der Waals energy values so that the complex tended to be positive or repulsive.

\section{Funding}

This research received no external funding.

\section{Acknowledgments}

The authors declare no acknowledgments

\section{Conflicts of Interest}

The authors declare no conflict of interest.

\section{References}

1. Gao, Y.; Guo, X.; Liu, Y.; Zhang, M.; Zhang, R.; Abbasi, A.M.; You, L.; Li, T.; Liu, R.H. Comparative assessment of phytochemical profile, antioxidant capacity and anti-proliferative activity in different varieties of brown rice (Oryza sativa L.). Lwt-Food Science and Technology 2018, 96, 19-25, https://doi.org/10.1016/j.lwt.2018.05.002.

2. Lang, G.H.; Lindemann, I.d.S.; Ferreira, C.D.; Hoffmann, J.F.; Vanier, N.L.; de Oliveira, M. Effects of drying temperature and long-term storage conditions on black rice phenolic compounds. Food Chemistry 2019, 287, 197-204, https://doi.org/10.1016/j.foodchem.2019.02.028.

3. Sheremet, M.I.; Sydorchuk, L.P; Shidlovskyi, V.O; Desiateryk, V.I.; Kovalenko, A.E.; Shevchenko, S.I,; Zavgorodnyi, S.M.; Tkachuk, N.P.; Piddubna, A.A. The activity of proliferation and apoptosis of thyrocytes in the thyroid tissue of patients of nodular goiter with autoimmune thyroiditis considering the polymorphism of the BCL-2 (RS17759659), CTLA-4 (RS231775) APO-1/FAS (RS2234767) genes. Biointerface Research in Applied Chemistry 2020, 10, 5201-5208, https://doi.org/10.33263/BRIAC102.201208.

4. Ram, G.; Sharma, V.R.; Sheikh, I.; Sankhyan, A.; Sankhyan, D.; Sharma, A.K. Anti-cancer potential of natural products: recent trends, scope and relevance. Letters in Applied NanoBioScience 2020, 9 ,902-907, https://doi.org/10.33263/LIANBS91.902907.

5. Penthala, N.R.; Bommagani, S.; Janganati, V.; MacNicol, K.B.; Cragle, C.E.; Madadi, N.R.; Hardy, L.L.; MacNicol, A.M.; Crooks, P.A. Heck products of parthenolide and melampomagnolide-B as anticancer modulators that modify cell cycle progression. European Journal of Medicinal Chemistry 2014, 85, 517525, https://doi.org/10.1016/j.ejmech.2014.08.022.

6. Mollaamin, F.; Naeimi, M.; Monajjemi, M. Vinblastine and vincristine as anticancer molecules stopping the tubulin dimers. Letters in Applied NanoBioScience 2020, 9, 870-874, https://doi.org/10.33263/LIANBS91.870874.

7. Cho, S.H.; Seung, B.J.; Kim, S.H.; Lim, H.Y.; Sur, J.H. Overexpression and Mutation of p53 Exons 4-8 in Canine Intestinal Adenocarcinoma. Journal of Comparative Pathology 2020, 175, 79-84, https://doi.org/10.1016/j.jcpa.2019.12.008.

8. $\quad$ Mori, S.; Patel, R.D.; Ahmad, S.; Varela, J.; Smith, T.; Altoos, R.; Shen, Q.; Goldstein, S.C.; Persky, D.O. Aggressive Leukemic Non-Nodal Mantle Cell Lymphoma With P53 Gene Rearrangement/Mutation is Highly Responsive to Rituximab/Ibrutinib Combination Therapy. Clinical Lymphoma, Myeloma and Leukemia 2019, 19, e93-e97, https://doi.org/10.1016/j.clml.2018.11.007.

9. Lian, J.; Xia, L.; Chen, Y.; Zheng, J.; Ma, K.; Luo, L.; Ye, F. Aldolase B impairs DNA mismatch repair and induces apoptosis in colon adenocarcinoma. Pathology - Research and Practice 2019, 215, https://doi.org/10.1016/j.prp.2019.152597.

10. Sengupta, S.; Krishnan, M.A.; Pandit, A.; Dudhe, P.; Sharma, R.; Chelvam, V. Tyrosine-based asymmetric urea ligand for prostate carcinoma: Tuning biological efficacy through in silico studies. Bioorganic Chemistry 2019, 91, https://doi.org/10.1016/j.bioorg.2019.103154.

11. Mazaheri, S.; Nafian, D.F. Modeling of membrane protein serpentin receptor with SWISS MODEL software. 
Clinical Biochemistry 2011, 44, S321, https://doi.org/10.1016/j.clinbiochem.2011.08.786.

12. Rocque, M.; Duwe, G. Rampage shootings: an historical, empirical, and theoretical overview. Current Opinion in Psychology 2018, 19, 28-33, https://doi.org/10.1016/j.copsyc.2017.03.025.

13. Meekrathok, P.; Thongsom, S.; Aunkham, A.; Kaewmaneewat, A.; Kitaoku, Y.; Choowongkomon, K.; Suginta, W. Novel GH-20 $\beta$-N-acetylglucosaminidase inhibitors: Virtual screening, molecular docking, binding affinity, and anti-tumor activity. International Journal of Biological Macromolecules 2020, 142, 503-512, https://doi.org/10.1016/j.ijbiomac.2019.09.122.

14. Zhang, C.; Freddolino, P.L.; Zhang, Y. COFACTOR: improved protein function prediction by combining structure, sequence and protein-protein interaction information. Nucleic Acids Res 2017, 45, W291-W299, https://doi.org/10.1093/nar/gkx366.

15. Daniyan, M.O.; Ojo, O.T. In silico identification and evaluation of potential interaction of Azadirachta indica phytochemicals with Plasmodium falciparum heat shock protein 90. Journal of Molecular Graphics and Modelling 2019, 87, 144-164, https://doi.org/10.1016/j.jmgm.2018.11.017.

16. Martinez, X.; Krone, M.; Alharbi, N.; Rose, A.S.; Laramee, R.S.; O'Donoghue, S.; Baaden, M.; Chavent, M. Molecular Graphics: Bridging Structural Biologists and Computer Scientists. Structure 2019, 27, 1617-1623, https://doi.org/10.1016/j.str.2019.09.001.

17. Zhu, J.; Li, K.; Wu, H.; Li, W.; Sun, Q. Multi-spectroscopic, conformational, and computational atomiclevel insights into the interaction of $\beta$-lactoglobulin with apigenin at different $\mathrm{pH}$ levels. Food Hydrocolloids 2020, 105, https://doi.org/10.1016/j.foodhyd.2020.105810.

18. Arba, M.; Pangan, A.R.; Yanuar, A. The search for peptide deformylase inhibitor from Indonesian Medicinal Plant Database: an in-silico investigation. Biointerface Research in Applied Chemistry 2020, 10, 5117-5121, https://doi.org/10.33263/BRIAC102.117121.

19. Kim, S. Public chemical databases. Encycl. Bioinforma. Comput. Biol. ABC Bioinforma. 2-18, 1-3, 628639, https://doi.org/10.1016/B978-0-12-809633-8.20192-1.

20. Xiang, Z. Advances in homology protein structure modeling. Curr Protein Pept Sci 2006, 7, 217-227, https://doi.org/10.2174/138920306777452312.

21. Souza-Cácares, M.B.; Fialho, A.L.L.; Silva, W.A.L.; Cardoso, C.J.T.; Pöhland, R.; Martins, M.I.M.; MeloSterza, F.A. Oocyte quality and heat shock proteins in oocytes from bovine breeds adapted to the tropics under different conditions of environmental thermal stress. Theriogenology 2019, 130, 103-110, https://doi.org/10.1016/j.theriogenology.2019.02.039.

22. Bielytskyi, P.; Gräsing, D.; Zahn, S.; Mote, K.R.; Alia, A.; Madhu, P.K.; Matysik, J. Assignment of NMR resonances of protons covalently bound to photochemically active cofactors in photosynthetic reaction centers by 13C-1H photo-CIDNP MAS-J-HMQC experiment. Journal of Magnetic Resonance 2019, 298, 64-76, https://doi.org/10.1016/j.jmr.2018.11.013.

23. Lovell, S.C.; Davis, I.W.; Arendall, W.B.; Paul, I.W.B.; Word, J.M. Structure validation by C alpha geometry. Proteins-Structure Funct. Genet. 2003, 50, 437-450, https://doi.org/10.1002/prot.10286.

24. Zhao, W.; He, L.; Xiang, T.-L.; Tang, Y.-J. Discover 4ß-NH-(6-aminoindole)-4-desoxy-podophyllotoxin with nanomolar-potency antitumor activity by improving the tubulin binding affinity on the basis of a potential binding site nearby colchicine domain. European Journal of Medicinal Chemistry 2019, 170, 7386, https://doi.org/10.1016/j.ejmech.2019.03.006.

25. Kovačević, S.; Karadžić, M.; Podunavac-Kuzmanović, S.; Jevrić, L. Binding affinity toward human prion protein of some anti-prion compounds - Assessment based on QSAR modeling, molecular docking and non-parametric ranking. European Journal of Pharmaceutical Sciences 2018, 111, 215-225, https://doi.org/10.1016/j.ejps.2017.10.004.

26. Průša, V.; Rajagopal, K.R.; Tůma, K. Gibbs free energy based representation formula within the context of implicit constitutive relations for elastic solids. International Journal of Non-Linear Mechanics 2020, 121, https://doi.org/10.1016/j.ijnonlinmec.2020.103433.

27. Tang, B.; Wang, Y.T.; Peng, X.L.; Zhang, L.H.; Jia, C.S. Efficient predictions of Gibbs free energy for the gases $\mathrm{CO}, \mathrm{BF}$, and gaseous BBr. Journal of Molecular Structure 2020, 1199, https://doi.org/10.1016/j.molstruc.2019.126958.

28. Lee, A.; Lee, K.; Kim, D. Using reverse docking for target identification and its applications for drug discovery. Expert Opinion on Drug Discovery 2016, 11, 707-715, https://doi.org/10.1080/17460441.2016.1190706

29. Ahmed, M.B.; Zhou, J.L.; Ngo, H.H.; Johir, M.A.H.; Sun, L.; Asadullah, M.; Belhaj, D. Sorption of hydrophobic organic contaminants on functionalized biochar: Protagonist role of $\pi$ - $\pi$ electron-donoracceptor interactions and hydrogen bonds. Journal of Hazardous Materials 2018, 360, 270-278, https://doi.org/10.1016/j.jhazmat.2018.08.005.

30. Fotoran, W.L.; Müntefering, T.; Kleiber, N.; Miranda, B.N.M.; Liebau, E.; Irvine, D.J.; Wunderlich, G. A multilamellar nanoliposome stabilized by interlayer hydrogen bonds increases antimalarial drug efficacy. Nanomedicine: Nanotechnology, Biology and Medicine 2019, https://doi.org/10.1016/j.nano.2019.102099. 